\title{
Long-term effect of cinacalcet hydrochloride on abdominal aortic calcification in patients on hemodialysis with secondary hyperparathyroidism
}

This article was published in the following Dove Press journal: International Journal of Nephrology and Renovascular Disease 18 December 2013

Number of times this article has been viewed

\author{
Kazunori Nakayama ${ }^{1,2}$ \\ Kazushi Nakao ${ }^{1,2}$ \\ Yuji Takatori ${ }^{1,2}$ \\ Junko Inoue' \\ Shoichirou Kojo' \\ Shigeru Akagi ${ }^{1,2}$ \\ Masaki Fukushima ${ }^{2}$ \\ Jun Wada' \\ Hirofumi Makino' \\ 'Department of Medicine and \\ Clinical Science, Okayama University \\ Graduate School of Medicine, \\ Dentistry and Pharmaceutical \\ Sciences, ${ }^{2}$ Shigei Medical Research \\ Hospital, Okayama, Japan
}

Background: Secondary hyperparathyroidism (SHPT) is one of the common complications in dialysis patients, and is associated with increased risk of vascular calcification. The effects of cinacalcet hydrochloride treatment on bone and mineral metabolism have been previously reported, but the benefit of cinacalcet on vascular calcification remains uncertain. The aim of this study was to evaluate the impact of cinacalcet on abdominal aortic calcification in dialysis patients.

Subjects and methods: Patients were on maintenance hemodialysis with insufficiently controlled SHPT (intact parathyroid hormone $[\mathrm{PTH}]>180 \mathrm{pg} / \mathrm{mL}$ ) by conventional therapies. All subjects were initially administered $25 \mathrm{mg}$ cinacalcet daily, with concomitant use of calcitriol analogs. Abdominal aortic calcification was annually evaluated by calculating aortic calcification area index (ACAI) using multidetector computed tomography (MDCT), from 12 months before to 36 months after the initiation of cinacalcet therapy.

Results: Twenty-three patients were analyzed in this study. The mean age was $59.0 \pm 8.7$ years, $34.8 \%$ were women, and the mean dialysis duration was $163.0 \pm 76.0$ months. After administration of cinacalcet, serum levels of intact PTH, phosphorus, and calcium significantly decreased, and mean Ca $\times$ P values significantly decreased from $67.4 \pm 7.9 \mathrm{mg}^{2} / \mathrm{dL}^{2}$ to $52 \pm 7.7 \mathrm{mg}^{2} / \mathrm{dL}^{2}$. Although the ACAI value did not decrease during the observation period, the increase in ACAI between 24 months and 36 months after cinacalcet administration was significantly suppressed.

Conclusion: Long-term administration of cinacalcet was associated with reduced progression of abdominal aortic calcification, and achieving appropriate calcium and phosphorus levels may reduce the rates of cardiovascular events and mortality in patients on hemodialysis.

Keywords: abdominal aortic calcification, cinacalcet hydrochloride, hemodialysis

\section{Introduction}

Patients with chronic kidney disease (CKD) undergoing dialysis have a higher risk of cardiovascular disease and mortality. ${ }^{1}$ Vascular calcification is frequently observed among patients with CKD, and associations between vascular calcification and increased risk of mortality have been reported in several studies. ${ }^{2-5}$ Secondary hyperparathyroidism (SHPT) is a common complication observed in dialysis patients. ${ }^{6}$ Goodman et al reported that elevation of calcium-phosphorus product is associated with cardiovascular events and vascular calcification, ${ }^{7}$ and mineral and bone disorders induced by SHPT have been considered to increase the risk of vascular calcification. Also, a high serum parathyroid hormone (PTH) concentration is associated with cardiovascular events and mortality. ${ }^{8-11}$

Cinacalcet hydrochloride (cinacalcet) is a calcimimetic agent that allosterically modulates the calcium-sensing receptor. It reduces serum PTH concentrations, and 
also decreases serum calcium and phosphorus concentrations simultaneously. To date, there have been several reports regarding treatment with cinacalcet easily achieving the target range of calcium, phosphorus, and PTH concentrations compared to conventional therapy for SHPT. ${ }^{12-15}$ In animal studies, pleiotropic effects of cinacalcet, such as improvement of parathyroid hyperplasia, osteitis fibrosa, osteoporosis, and vascular calcification have been shown. ${ }^{16-22}$ In dialysis patients, Tsuruta et al demonstrated improved coronary artery calcification scores by administration of cinacalcet. ${ }^{23}$ More recently, Raggi et al suggested that cinacalcet may attenuate calcification of coronary artery in patients on hemodialysis in the ADVANCE (Study to Evaluate Cinacalcet Plus LowDose Vitamin D on Vascular Calcification in Subjects with Chronic Kidney Disease Receiving Hemodialysis) trial, ${ }^{24}$ but investigations in regard to the effect of cinacalcet on vascular calcification are still quite few, and the clinical benefit of cinacalcet remains uncertain.

The aim of this study was to evaluate the associations between treatment with cinacalcet and the progression of vascular calcification among patients on maintenance hemodialysis with inadequately controlled SHPT by conventional therapies.

\section{Subjects and methods Patient selection}

Subjects were 18 years or older, had undergone hemodialysis for $>12$ months at Shigei Medical Research Hospital, Okayama, Japan, and had biochemical evidence of SHPT with intact PTH concentrations $>180 \mathrm{pg} / \mathrm{mL}$ during treatment with calcitriol analogs. Albumin-corrected serum calcium concentrations were $>8.4 \mathrm{mg} / \mathrm{dL}$, and aortic calcification area index $(\mathrm{ACAI})^{25}$ at screening was 0 or $>60$ in all subjects, as measured

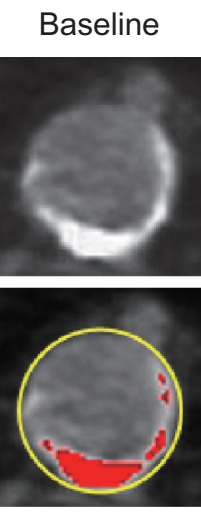

$12.8 \%$

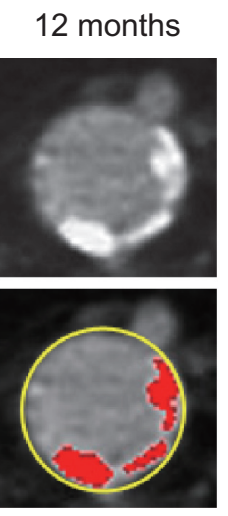

$15.4 \%$

by multidetector computed tomography (MDCT). The trial was conducted according to the principles of the Declaration of Helsinki. The study protocol was approved by the ethics committee of Shigei Medical Research Hospital, and written informed consent was obtained from all participants.

\section{Study protocol}

The current investigation was a prospective cohort study in a single hospital, with all subjects treated with cinacalcet hydrochloride at a starting dose of $25 \mathrm{mg} /$ day. The dose was allowed to be adjusted in an attempt to achieve the target ranges specified in the Japanese Society for Dialysis Therapy (JSDT) guideline (calcium 8.4-10.0 mg/dL, phosphorus 3.5-6.0 mg/dL, intact PTH 60-180 pg/mL). ${ }^{26}$ Changes in cinacalcet dosage were recorded throughout the follow-up period, and the maximum dose of cinacalcet administered was $100 \mathrm{mg}$. For conventional therapy, the subjects received various doses of calcitriol analogs either orally or intravenously. Concomitant treatment with phosphate binders was also permitted and could be adjusted without restriction throughout the study. The duration of each dialysis treatment was 4-4.5 hours, and blood samples were drawn once a month at the beginning of the first hemodialysis session of the week. Systolic and diastolic blood pressures were measured in the supine position after 10-15 minutes' rest.

\section{Imaging evaluation}

We measured the $\mathrm{ACAI}^{25}$ using MDCT from 12 months before cinacalcet was started, and every 12 months thereafter, until 36 months after cinacalcet administration. Thus, we evaluated the percent annual change in the ACAI during the follow-up period. In Figure 1, the change in ACAI score in a representative case is shown. Using MDCT, the area above

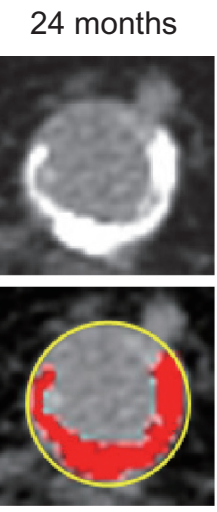

$26.8 \%$
36 months

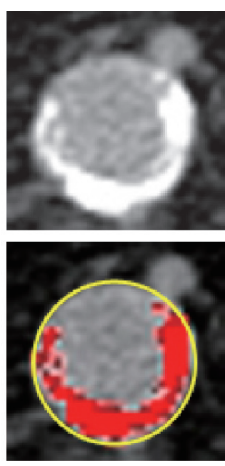

$30.4 \%$

Figure I Aortic calcification area index (ACAI) in a representative case from baseline to 36 months after cinacalcet administration. ACAI is measured as follows. The area above the bifurcation of the common iliac artery is scanned ten times at I cm intervals. These scans are then analyzed by Image (National Institutes of Health, Bethesda, MD, USA) to calculate the area of calcification in the abdominal aorta and the cross-sectional area of the aorta to calculate the calcified area as a percentage. The ACAI is expressed as the average calcification index of ten scans. 
bifurcation of the common iliac artery is scanned ten times at $1 \mathrm{~cm}$ intervals. These scans are then analyzed by Image $\mathrm{J}^{27}$ (National Institutes of Health, Bethesda, MD, USA) to calculate the area of calcification in the abdominal aorta and the cross-sectional area of the aorta to calculate the calcified area as a percentage. The ACAI is expressed as the average calcification index of ten scans.

\section{Statistical analysis}

Results are reported as means \pm standard deviation, unless otherwise indicated. Annual change in ACAI score, serum albumin-corrected calcium, serum phosphorus, calciumphosphorus product, and intact PTH values were analyzed by repeated measures analysis of variance followed by Tukey's post hoc test. Also, the change in ACAI/year was analyzed by unpaired $t$-test between the group of treatment with lanthanum carbonate and the others. Stepwise multivariate regression analysis was performed using \%ACAI (month 24/month 36/ month $-12 / 0)=($ ACAI [month 36] $/$ ACAI [month 24] $) /($ ACAI [month 0]/ACAI [month -12]) as a dependent variable. Independent variables were sex and absolute changes in phosphorus, calcium-phosphorus product, and intact PTH from baseline to 36 months after cinacalcet administration. Doses of calcitriol analogs considered to be equivalent were $10 \mu \mathrm{g}$ maxacalcitol $=1.5 \mu \mathrm{g}$ calcitriol, and all results for injectable active calcitriol analog dosages are presented as calcitriol equivalents. Statistical analyses were performed by SPSS software (version 20.0; IBM, Armonk, NY, USA). For all comparisons, $P<0.05$ was considered statistically significant.

\section{Results}

\section{Study population and baseline results}

Of 47 participants in the study, 43 completed 36 months of treatment. The reasons for early withdrawal included death $(n=3)$ and kidney transplantation $(n=1)$. None of the deaths were considered related to cinacalcet. Of the 43 patients who completed the study, no MDCT $\operatorname{scan}(\mathrm{n}=12)$, ACAI $>60(\mathrm{n}=2)$, ACAI $=0(n=2)$, and twisted abdominal aorta $(n=4)$ were excluded, because their aortas were not appropriate to assess the progression of calcification. Finally, a total of 23 subjects were available for efficacy analysis. Table 1 shows the baseline characteristics at month 0 . The mean age of 23 subjects who completed the study was $59.0 \pm 8.7$ years, $34.8 \%$ were women, and mean dialysis duration was $163.0 \pm 76.0$ months. All patients had intact PTH levels $>180 \mathrm{pg} / \mathrm{mL}$. Approximately $70 \%$ of the subjects were receiving injectable active calcitriol analogs at enrollment, and the mean dose was $1.56 \pm 1.26 \mu \mathrm{g} /$ week of calcitriol equivalents. Almost all were receiving phosphate binders.
Table I Baseline demographic and medication characteristics $(\mathrm{n}=23)$

\begin{tabular}{ll}
\hline Age (years) & $59 \pm 8.7$ \\
Sex (female, \%) & 34.8 \\
Hemodialysis duration (months) & $163 \pm 76$ \\
Diabetes mellitus (\%) & 13 \\
BMI $\left(\mathrm{kg} / \mathrm{m}^{2}\right)$ & $21.12 \pm 3.31$ \\
Systolic blood pressure $(\mathrm{mmHg})$ & $135 \pm 17.9$ \\
Diastolic blood pressure $(\mathrm{mmHg})$ & $73.2 \pm 11.3$ \\
History of calcium carbonate use $(\%)$ & 78.3 \\
History of sevelamer hydrochloride use $(\%)$ & 13 \\
History of lanthanum carbonate use $(\%)$ & 0 \\
Baseline vitamin D use $(\%)$ & 69.6 \\
Serum intact PTH $(\mathrm{pg} / \mathrm{mL})$ & $473.4 \pm 220.1$ \\
Corrected serum calcium $(\mathrm{mg} / \mathrm{dL})$ & $10.1 \mathrm{I} \pm 0.59$ \\
Serum phosphorus $(\mathrm{mg} / \mathrm{dL})$ & $6.59 \pm 0.8 \mathrm{I}$ \\
Serum albumin $(\mathrm{g} / \mathrm{dL})$ & $3.64 \pm 0.29$ \\
Serum ALP $(\mathrm{U} / \mathrm{L})$ & $262.1 \pm 89.2$
\end{tabular}

Note: Values are means \pm standard deviation.

Abbreviations: BMI, body mass index; PTH, parathyroid hormone; ALP, alkaline phosphatase.

\section{Effect of cinacalcet on intact PTH and mineral metabolism}

Figure 2 shows the change in serum levels of intact PTH, calcium, and phosphorus from baseline to the end of the follow-up period. Subjects started receiving $25 \mathrm{mg}$ /day of cinacalcet at baseline, and the mean dosage of cinacalcet was $46.2 \pm 29.8 \mathrm{mg} /$ day at 36 months. None of the subjects had to discontinue treatment with cinacalcet due to side effects or noncompliance. After administration of cinacalcet, serum intact PTH levels decreased from $473.4 \pm 220.1 \mathrm{pg} / \mathrm{mL}$ at baseline to $163.0 \pm 94.8 \mathrm{pg} / \mathrm{mL}$ at 12 months (Figure 2A, $P<0.001$ ), and then remained stable throughout the study period. After 36 months of cinacalcet treatment, $78.3 \%$ of subjects achieved intact PTH concentration below the upper limit of the JSDT target range. The mean serum phosphorus concentration decreased from $6.7 \pm 0.8 \mathrm{mg} / \mathrm{dL}$ to $5.6 \pm 0.9 \mathrm{mg} / \mathrm{dL}$ (Figure 2B, $P<0.001$ ), and the mean corrected serum calcium concentration also decreased, from $10.1 \pm 0.6$ to $9.4 \pm 0.6 \mathrm{mg} / \mathrm{dL}$ (Figure $2 \mathrm{C}, P=0.001$ ). The mean $\mathrm{Ca} \times \mathrm{P}$ values were significantly decreased from $67.4 \pm 7.9 \mathrm{mg}^{2} / \mathrm{dL}^{2}$ to $52.0 \pm 7.7 \mathrm{mg}^{2} / \mathrm{dL}^{2}$ (Figure 2D, $P<0.001$ ). After 36 months of treatment, subjects who achieved $\mathrm{Ca} \times \mathrm{P}<55 \mathrm{mg}^{2} / \mathrm{dL}^{2}$ increased from $4.4 \%$ to $65.2 \%$.

\section{Use of calcitriol analogs and phosphate binders}

The use and dose of intravenous active calcitriol analogs remained largely unchanged from baseline to 36 months. Similarly, the percentages of the subjects taking sevelamer 

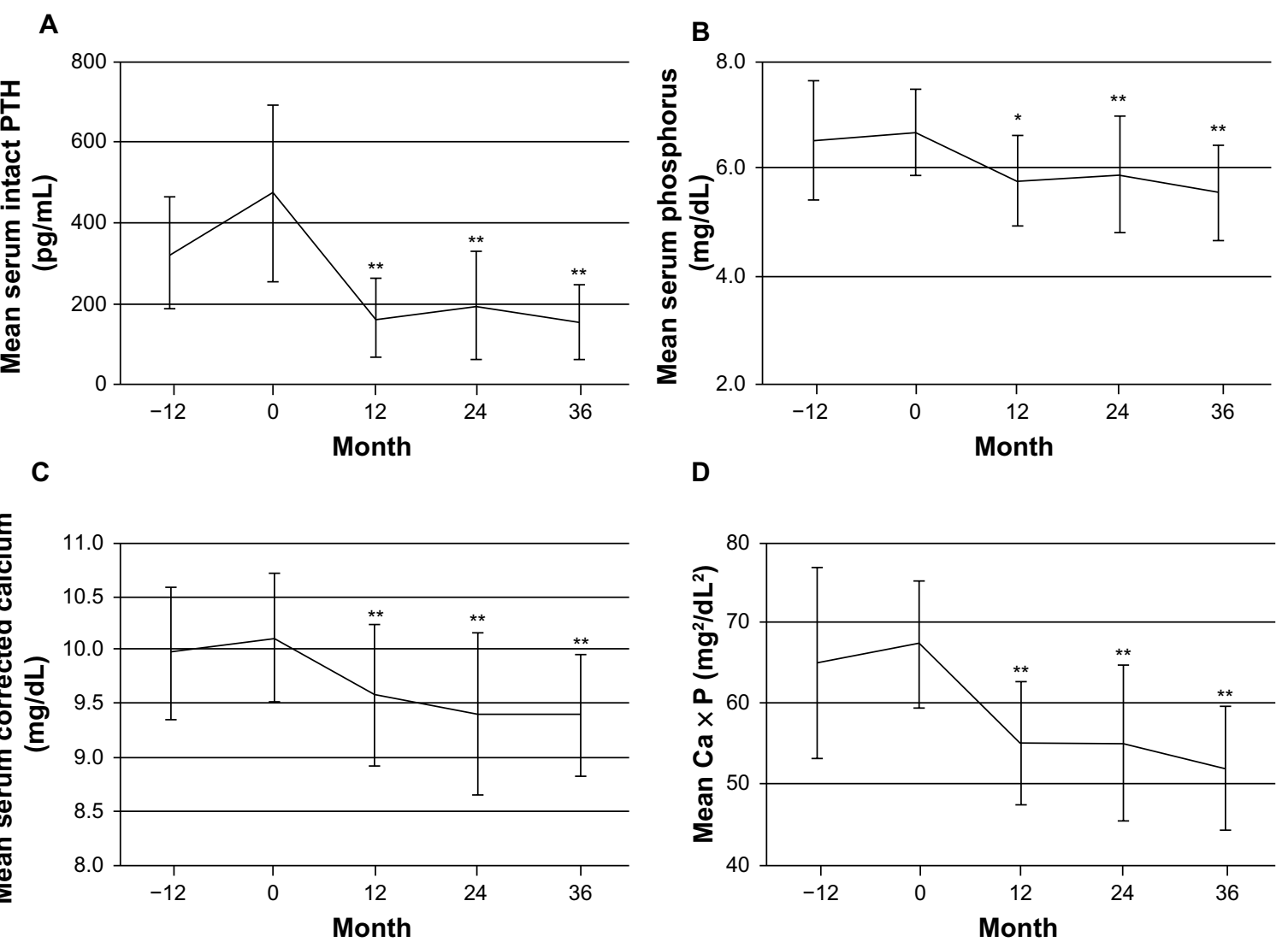

D

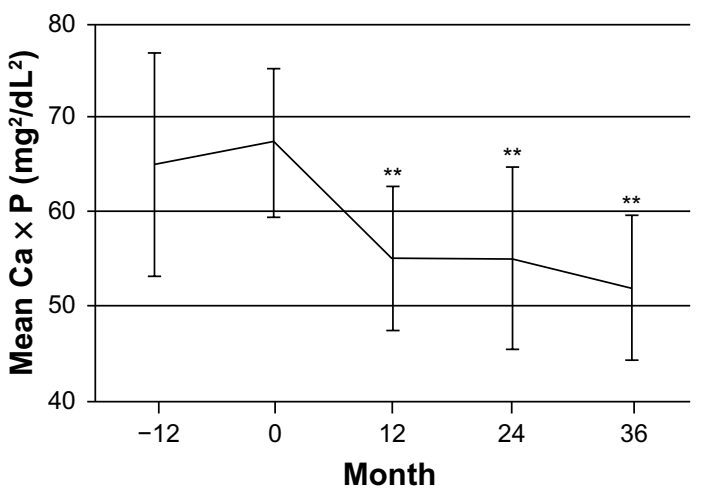

Figure 2 (A-D) Serum levels of intact parathyroid hormone (PTH), calcium, and phosphorus from baseline to the end of the follow-up period. After administration of cinacalcet, serum intact PTH levels decreased from $473.4 \pm 220.1 \mathrm{pg} / \mathrm{mL}$ at baseline to $163.0 \pm 97.0 \mathrm{pg} / \mathrm{mL}$ at 12 months $(P<0.00 \mathrm{I})(\mathbf{A})$ and then remained stable through the study period. The mean serum phosphorus concentration decreased from $6.7 \pm 0.8 \mathrm{mg} / \mathrm{dL}$ at baseline to $5.6 \pm 0.9 \mathrm{mg} / \mathrm{dL}$ at $36 \mathrm{months}(P<0.00 \mathrm{I})(\mathbf{B})$, and the mean corrected serum calcium concentration also decreased, from $10.1 \pm 0.6$ to $9.4 \pm 0.6 \mathrm{mg} / \mathrm{dL}(P=0.00 \mathrm{I})$ (C). The mean $\mathrm{Ca} \times \mathrm{P}$ values significantly decreased from $67.4 \pm 7.9 \mathrm{mg} / \mathrm{dL}^{2}$ to $52 \pm 7.7 \mathrm{mg}^{2} / \mathrm{dL}^{2}$ for 36 months $(P<0.00 \mathrm{I})(\mathbf{D}) * P<0.05 ; * * P<0.0$ I.

Abbreviations: $\mathrm{Ca}$, calcium; $\mathrm{P}$, inorganic phosphate.

hydrochloride and calcium carbonate were stable throughout the study period (Table 2). After 24 months of cinacalcet administration, $65.2 \%$ of the subjects were treated with lanthanum carbonate.

\section{Effect of cinacalcet on aortic calcification}

The change in ACAI score for an individual subject and mean values over the observation period are presented in
Figure $3 \mathrm{~A}$ and $\mathrm{B}$, respectively. The mean ACAI value was $21.4 \%$ at baseline, $23.9 \%$ at 12 months, $23.7 \%$ at 24 months, and $24.3 \%$ at 36 months (Figure $3 \mathrm{~B}$ ). The annual percentage changes in ACAI score from 12 months before cinacalcet administration to 36 months were $15.82 \pm 18.25$ (12 months before to baseline), $8.10 \pm 10.01$ (baseline to 12 months),

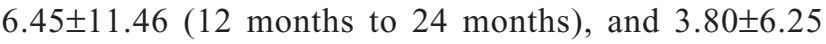
(24 months to 36 months) (Figure 4). Though ACAI values

Table 2 The changes of dosage of cinacalcet hydrochloride, intravenous calcitriol analogs, and phosphate binders during the study

\begin{tabular}{lllll}
\hline & Baseline & Month I2 & Month 24 & Month 36 \\
\hline Cinacalcet hydrochloride (mg/day) & $25 \pm 0$ & $48.9 \pm 27.4$ & $47.8 \pm 27.9$ & $46.2 \pm 29.8$ \\
Intravenous calcitriol analogs & & & & \\
Calcitriol dose equivalents ( $\mu \mathrm{g} /$ week) & $1.56 \pm 1.26$ & $1.41 \pm 1.22$ & $1.51 \pm 1.18$ & $1.53 \pm 1.18$ \\
$\quad$ Subjects (\%) & 70 & 74 & 74 & 74 \\
Calcium carbonate (g/day)* & $2.00 \pm 0.87$ & $2.00 \pm 0.95$ & $1.92 \pm 0.89$ & $2.03 \pm 0.92$ \\
$\quad$ Subjects (\%) & 78.3 & 78.3 & 82.6 & 78.3 \\
Sevelamer hydrochloride (g/day)* & $3.75 \pm 2.25$ & $3.45 \pm 2.09$ & $3.00 \pm 1.98$ & 13 \\
$\quad$ Subjects (\%) & 13 & 21.7 & 13 & $1.63 \pm 1.79$ \\
Lanthanum carbonate (g/day)* & 0 & 0 & $1.18 \pm 0.64$ & $1.15 \pm 0.67$ \\
$\quad$ Subjects (\%) & 0 & 0 & 65.2 & 65.2 \\
\hline
\end{tabular}

Notes: *Average daily doses in patients treated with each phosphate binder. Values are means \pm standard deviation. I.5 $\mu \mathrm{g}$ calcitriol $=10 \mu \mathrm{g}$ maxacalcitol. 
A

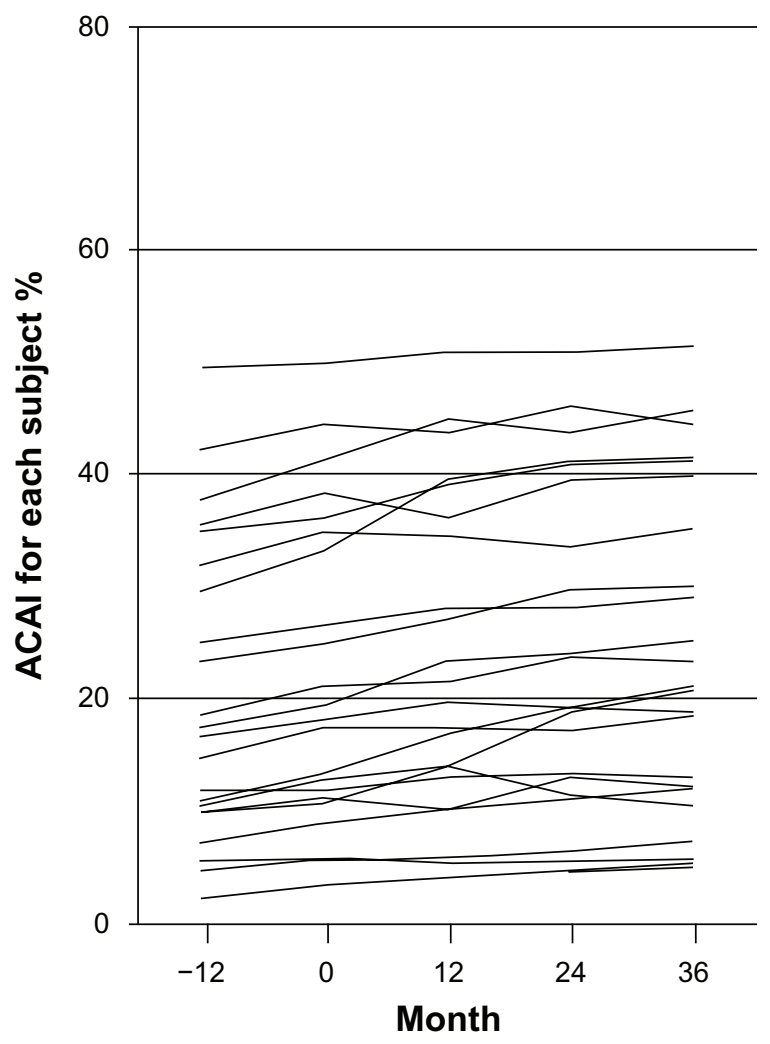

B

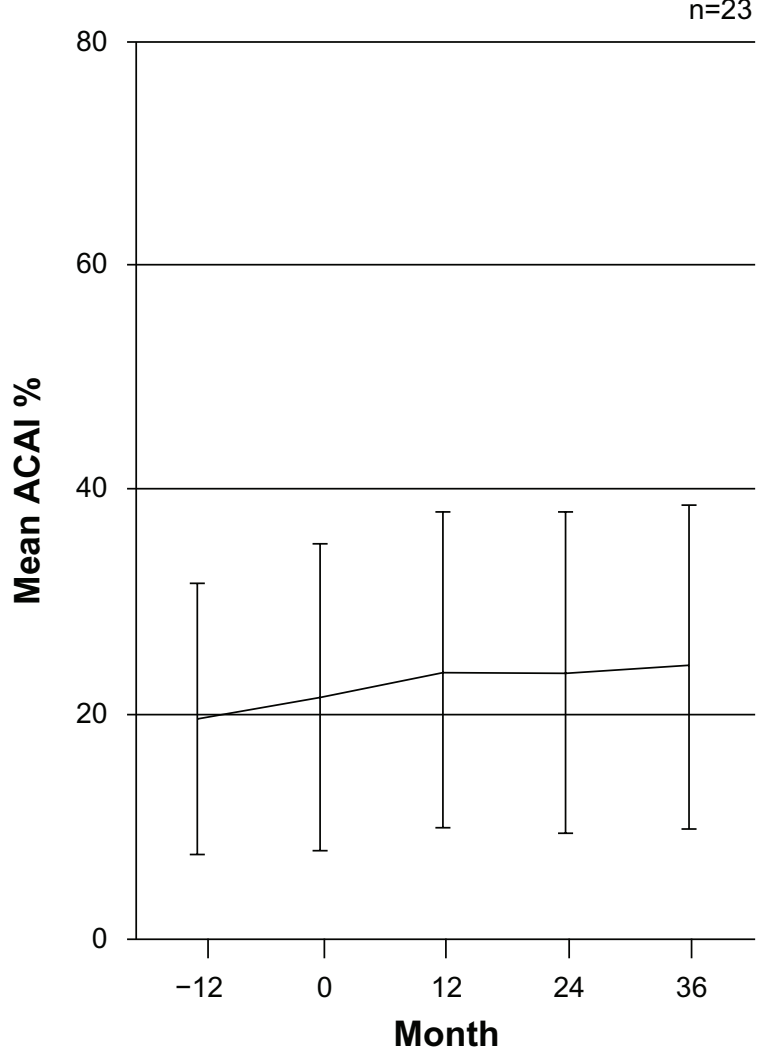

Figure 3 The change in aortic calcification area index (ACAl) from - 12 months to 36 months for an individual subject (A) and the mean ACAl value over the observation period (B). The mean ACAl value was $21.4 \%$ at baseline, $23.9 \%$ at 12 months, $23.7 \%$ at 24 months, and $24.3 \%$ at 36 months.

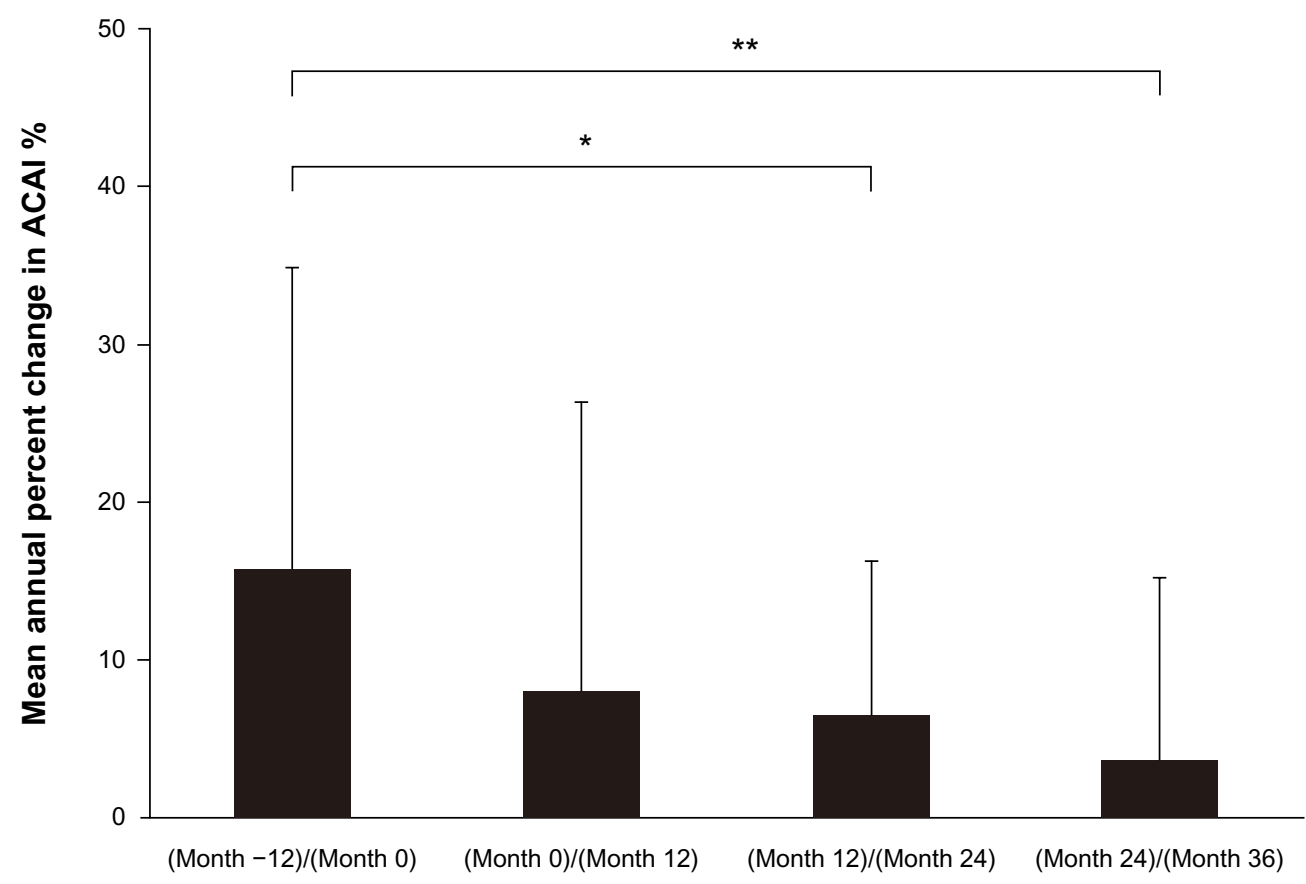

Figure 4 The annual percentage changes of aortic calcification area index (ACAl) from -12 months to 36 months. The values are $15.82 \pm 18.25$ ( -12 months to baseline), $8.10 \pm 10.01$ (baseline to 12 months), $6.45 \pm 11.46$ ( 12 months to 24 months) and $3.80 \pm 6.25$ ( 24 months to 36 months). The increase in ACAl/year from I2 months to 24 months was significantly suppressed, compared to that of -12 months to baseline $(P=0.017)$. Moreover, the increase in ACAl/year from 24 months to 36 months was significantly suppressed $(P=0.00 \mathrm{I}) * P<0.05 ; * * P<0.0 \mathrm{I}$. 
were not decreased in any of the subjects by cinacalcet administration, the percentage increase of ACAI/year was gradually suppressed. Especially, the increase in ACAI/year between 24 and 36 months was significantly suppressed compared to that of between 12 months before cinacalcet administration and baseline $(P=0.001)$.

\section{Factors associated with progression of aortic calcification}

To determine potential factors responsible for the suppression of increase in ACAI/year, we examined associations between percentage changes in $\mathrm{ACAI} /$ year and biochemical response to cinacalcet by univariate and multivariate linear regression models (Tables 3 and 4). Eventually, female sex and reduction in $\Delta \mathrm{P}$ or $\Delta \mathrm{Ca} \times \mathrm{P}$ were independent determinants of suppression of increase in ACAI scores. Additionally, there was no significant difference in the suppression of ACAI/year between the group treated with lanthanum carbonate $(n=15)$ and the other group $(n=8)$ (data not shown).

\section{Discussion}

Vascular and cardiac valve calcification are important predictors of cardiovascular disease and mortality among dialysis patients, ${ }^{28,29}$ and abdominal aortic calcification is also associated with coronary artery calcification, cardiovascular events, and mortality. ${ }^{2,3,30,31}$ Wilson et al reported

Table 3 Univariate regression analysis of factors associated with the percent change of ACAI between 24 months and 36 months, and between 12 months before cinacalcet administration and baseline

\begin{tabular}{|c|c|c|}
\hline & \multicolumn{2}{|c|}{$\begin{array}{l}\% \text { ACAI (month } 24 / 36 / \\
\text { month }-12 / 0 \text { )** }\end{array}$} \\
\hline & $R$ & P-value \\
\hline Age & 0.059 & 0.788 \\
\hline Sex & 0.533 & $0.009 *$ \\
\hline Diabetes mellitus & 0.094 & $0.67 \mid$ \\
\hline Hemodialysis duration & 0.340 & 0.112 \\
\hline $\mathrm{Ca}$ & 0.263 & 0.226 \\
\hline$\Delta \mathrm{Ca}$ & 0.029 & 0.895 \\
\hline$P$ & 0.340 & 0.113 \\
\hline$\Delta \mathrm{P}$ & 0.632 & $0.001 *$ \\
\hline $\mathrm{Ca} \times \mathrm{P}$ & 0.344 & 0.108 \\
\hline$\Delta \mathrm{Ca} \times \mathrm{P}$ & 0.622 & $0.002 *$ \\
\hline iPTH & 0.008 & 0.972 \\
\hline$\triangle \mathrm{iPTH}$ & 0.138 & 0.531 \\
\hline ALP & 0.096 & 0.664 \\
\hline$\Delta \mathrm{ALP}$ & 0.127 & 0.564 \\
\hline
\end{tabular}

Notes: $* P<0.05$; ** $[\mathrm{ACAI}$ (month 36)/ACAI (month 24)/ACAI (month 0)/ACAI (month-12)].

Abbreviations: ACAl, aortic calcification area index; ALP, alkaline phosphatase; $\mathrm{Ca}$, calcium; $\mathrm{P}$, inorganic phosphate; $\mathrm{PTH}$, intact parathyroid hormone.
Table 4 Stepwise multivariate regression analysis of factors associated with the percent change of ACAI between 24 months and 36 months, and between 12 months before cinacalcet administration and baseline

\begin{tabular}{|c|c|c|c|c|}
\hline $\begin{array}{l}\text { Dependent } \\
\text { variable }\end{array}$ & $\begin{array}{l}\text { Independent } \\
\text { variable }\end{array}$ & $\beta$ & $t$ & P-value \\
\hline$\% A C A I$ & $\Delta \mathrm{P}$ & 0.539 & 3.533 & 0.002 \\
\hline \multirow[t]{7}{*}{$\begin{array}{l}\text { (month } 24 / 36 / \\
\text { month }-12 / 0 \text { )* }\end{array}$} & $\begin{array}{l}\text { Sex (male:0, } \\
\text { female:I) }\end{array}$ & -0.41 & -2.688 & 0.014 \\
\hline & & \multicolumn{3}{|c|}{$\begin{array}{l}R^{2}=0.559, F \text { value } 12.68 I, \\
P<0.00 \text { I }\end{array}$} \\
\hline & $\Delta \mathrm{Ca} \times \mathrm{P}$ & 0.524 & 3.36 & 0.003 \\
\hline & $\begin{array}{l}\text { Sex (male:0, } \\
\text { female:I) }\end{array}$ & -0.407 & -2.608 & 0.017 \\
\hline & & \multicolumn{3}{|c|}{$\begin{array}{l}R^{2}=0.542, F \text { value } I I .850 \\
P<0.00 \text { I }\end{array}$} \\
\hline & $\Delta \mathrm{P}$ & 0.632 & 3.74 & 0.001 \\
\hline & & \multicolumn{3}{|c|}{$\begin{array}{l}R^{2}=0.400, F \text { value } 13.989 \\
P=0.001\end{array}$} \\
\hline
\end{tabular}

Note: *[ACAI (month 36)/ACAI (month 24)]/[ACAI (month 0)/ACAl (month -12)]. Abbreviations: $\mathrm{ACAl}$, aortic calcification area index; $\mathrm{Ca}$, calcium; $\mathrm{P}$, inorganic phosphate.

that abdominal aortic calcium deposits, detected by lumbar radiograms, are a marker of atherosclerotic disease and an independent predictor of subsequent vascular morbidity and mortality. ${ }^{32}$ At present, the effects of cinacalcet on coronary artery calcification have been tested in several studies, whereas little has been investigated regarding the effects of cinacalcet on abdominal aortic calcification. Therefore, we focused on changes of abdominal aortic calcification in patients on dialysis to assess the effects of cinacalcet on vascular calcification.

In our study protocol, we employed MDCT scans and evaluated changes of abdominal aortic calcification more precisely by calculating ACAI, while calcification was measured by plain lateral radiographs in the previous CORD (Calcification Outcome in Renal Disease) study. ${ }^{33}$ Moreover, to our knowledge, this is the first attempt to assess changes of vascular calcification in hemodialysis patients using MDCT for a period of 4 years. In addition, the studied population in the current study was relatively young and included fewer diabetes patients with longer dialysis duration compared with those in European and US registries.

To evaluate vascular calcification in hemodialysis patients, we have to take the effect of calcitriol analogs into account, since it has been suggested that calcitriol analog administration progresses calcification in a dose-dependent manner. In the ADVANCE study, ${ }^{24}$ patients on hemodialysis with SHPT were divided into a calcitriol analog group and a calcitriol analog plus cinacalcet group randomly, and they were observed for 52 weeks. The result suggested that cinacalcet attenuates the progression 
of coronary artery calcification score, cardiac valve calcification, and calcification of the thoracic aorta. However, doses of calcitriol analogs were significantly decreased in the calcitriol analog plus cinacalcet group during the study, indicating that administration of calcitriol analogs might affect the progression of vascular calcification. On the other hand, in the EVOLVE (EValuation Of Cinacalcet $\mathrm{HCl}$ Therapy to Lower CardioVascular Events) study, there were no significant differences in the incidence of cardiovascular events between the cinacalcet group and placebo group after 64 months of cinacalcet administration. Actually, baseline characteristics between the two groups, including cardiovascular morbidity, were imbalanced, and many patients in the cinacalcet group had their treatment aborted. ${ }^{34}$ Even after completion of these trials, further investigation is needed to clarify the clinical benefits of cinacalcet.

In the current study, the influence of calcitriol analogs on vascular calcification can be excluded, in contrast to the ADVANCE study, since doses of calcitriol analogs were stable during the study period. Thus, it is suggested that slower progression of aortic calcification in our subjects can be attributed to the administration of cinacalcet. The actual ACAI value did not decrease after cinacalcet administration, but the annual change of the ACAI from 24 to 36 months was found to be significantly suppressed compared to from 12 months before to baseline. Though almost all of the patients were outside the target levels of serum calcium and phosphorus at baseline, apparent improvement in those levels was observed after 36 months of cinacalcet administration. Moreover, univariate and multivariate linear regression analyses revealed that lower levels of serum phosphorus were associated with the suppression of vascular calcification. Based on these results, the progression of vascular calcification may be suppressed by correcting the levels of phosphorus properly via the effect of cinacalcet, and it is suggested that starting cinacalcet at an earlier stage of hemodialysis could prevent progression of vascular calcification.

Though several reports have suggested the effect of cinacalcet against vascular calcification, there remains a fundamental question as to how calcimimetics work on the vascular wall in dialysis patients. The calcium-sensing receptor is a target for therapeutic manipulation, since it proved to be expressed in aortic smooth-muscle cells. In a recent animal experiment, cinacalcet was considered to be a potential arterial relaxant candidate, acting predominantly by inhibiting $\mathrm{Ca}^{2+}$ influx through L-type $\mathrm{Ca}^{2+}$ channels into vascular smooth muscle. ${ }^{35}$ However, whether cinacalcet has a direct effect on smooth-muscle cell calcification remains uncertain, and this question needs to be elucidated in future investigations. Recently, cinacalcet has been reported to suppress serum fibroblast growth factor- 23 levels and reduce serum phosphate concentration. ${ }^{36}$

There are several limitations in the current clinical investigation. The sample size of the enrolled patients was small, the study was not randomized or double-blinded, and there was no control group. The target range of intact PTH at 60-180 $\mathrm{pg} / \mathrm{mL}$ was recommended in the JSDT guideline at the initiation of the study, but it was revised in 2012, and the target levels of intact PTH in the patients undergoing hemodialysis is recommended to be $60-240 \mathrm{pg} / \mathrm{mL} \cdot{ }^{37}$ Since the target was rather lower compared with Kidney Disease Outcomes Quality Initiative guidelines $(150-300 \mathrm{pg} / \mathrm{mL}$ ) and Kidney Disease Improving Global Outcomes guidelines (two to nine times the upper normal limit for the assay), it can be associated with a high risk for adynamic bone disease. In the evaluation of aorta calcification, the ACAI was measured by using MDCT. The area above bifurcation of the common iliac artery was scanned ten times at $1 \mathrm{~cm}$ intervals, but the current method has not been validated by clinical studies with larger populations. In addition, the ACAI reflects both intimal and medial calcification, and fails to measure intimal calcification specifically, which is more tightly associated with atherosclerosis. Finally, we could not completely rule out the beneficial effects of lanthanum carbonate and other phosphate binders on the progression of aorta calcification. Lanthanum carbonate became commercially available in our country 12 months after our investigation started, and actually $65.2 \%$ of the subjects had been administrated lanthanum carbonate at the end of the study.

\section{Conclusion}

We clearly demonstrated that use of cinacalcet obviously suppressed the progression of abdominal aortic calcification throughout the observation period using MDCT imaging. Longer-term, ie, 3-year, administration of cinacalcet may reduce arterial calcification and achieve appropriate calcium and phosphorus levels, bringing about a reduction in the incidence of cardiovascular events and mortality in patients on hemodialysis. The percentage of calcification increased with time, even with cinacalcet treatment, and the therapy may be palliative rather than curative. To conclude that cinacalcet is truly clinically beneficial in preventing vascular calcification, larger randomized clinical trials with properly optimized protocols, such as early initiation of the agent, are required.

\section{Disclosure}

JW is a consultant for Boehringer Ingelheim and receives speaker honoraria from Novartis. HM is a consultant 
for AbbVie, Teijing, and Astellas, and receives speaker honoraria from Astellas, MSD, Takeda, and Mitsubishi Tanabe, and receives grant support from Astellas, Daiichi Sankyo, Dainippon Sumitomo, MSD, Novo Nordisk, Takeda, and Kyowa Hakko Kirin. The rest of the authors report no conflicts of interest in this work.

\section{References}

1. Moe SM, Chen NX. Pathophysiology of vascular calcification in chronic kidney disease. Circ Res. 2004;95(6):560-567.

2. Okuno S, Ishimura E, Kitatani K, et al. Presence of abdominal aortic calcification is significantly associated with all-cause and cardiovascular mortality in maintenance hemodialysis patients. Am J Kidney Dis. 2007;49(3):417-425.

3. Blacher J, Guerin AP, Pannier B, Marchais SJ, London GM. Arterial calcifications, arterial stiffness, and cardiovascular risk in end-stage renal disease. Hypertension. 2001;38(4):938-942.

4. London GM, Guerin AP, Marchais SJ, Metivier F, Pannier B, Adda H. Arterial media calcification in end-stage renal disease: impact on all-cause and cardiovascular mortality. Nephrol Dial Transplant. 2003;18(9):1731-1740.

5. Spiegel DM, Raggi P, Smits G, Block GA. Factors associated with mortality in patients new to haemodialysis. Nephrol Dial Transplant. 2007;22(12):3568-3572.

6. Palmer SC, Hayen A, Macaskill P, et al. Serum levels of phosphorus, parathyroid hormone, and calcium and risks of death and cardiovascular disease in individuals with chronic kidney disease: a systematic review and meta-analysis. JAMA. 2011;305(11):1119-1127.

7. Goodman WG, Goldin J, Kuizon BD, et al. Coronary-artery calcification in young adults with end-stage renal disease who are undergoing dialysis. N Engl J Med. 2000;342(20):1478-1483.

8. Block GA, Klassen PS, Lazarus JM, Ofsthun N, Lowrie EG, Chertow GM. Mineral metabolism, mortality, and morbidity in maintenance hemodialysis. J Am Soc Nephrol. 2004;15(8):2208-2218.

9. Ganesh SK, Stack AG, Levin NW, Hulbert-Shearon T, Port FK. Association of elevated serum $\mathrm{PO}(4), \mathrm{Ca} \times \mathrm{PO}(4)$ product, and parathyroid hormone with cardiac mortality risk in chronic hemodialysis patients. J Am Soc Nephrol. 2001;12(10):2131-2138.

10. Pasieka JL, Parsons LL. A prospective surgical outcome study assessing the impact of parathyroidectomy on symptoms in patients with secondary and tertiary hyperparathyroidism. Surgery. 2000;128(4):531-539.

11. Sherrard DJ, Hercz G, Pei Y, et al. The spectrum of bone disease in end-stage renal failure - an evolving disorder. Kidney Int. 1993;43(2): 436-442.

12. El-Shafey EM, Alsahow AE, Alsaran K, Sabry AA, Atia M. Cinacalcet hydrochloride therapy for secondary hyperparathyroidism in hemodialysis patients. Ther Apher Dial. 2011;15(6):547-555.

13. Lindberg JS, Culleton B, Wong G, et al. Cinacalcet $\mathrm{HCl}$, an oral calcimimetic agent for the treatment of secondary hyperparathyroidism in hemodialysis and peritoneal dialysis: a randomized, double-blind, multicenter study. J Am Soc Nephrol. 2005;16(3):800-807.

14. Block GA, Martin KJ, de Francisco AL, et al. Cinacalcet for secondary hyperparathyroidism in patients receiving hemodialysis. $N$ Engl $J$ Med. 2004;350(15):1516-1525.

15. Moe SM, Chertow GM, Coburn JW, et al. Achieving NKF-K/DOQI bone metabolism and disease treatment goals with cinacalcet $\mathrm{HCl}$. Kidney Int. 2005;67(2):760-771.

16. Colloton M, Shatzen E, Miller G, et al. Cinacalcet $\mathrm{HCl}$ attenuates parathyroid hyperplasia in a rat model of secondary hyperparathyroidism. Kidney Int. 2005;67(2):467-476.

17. Miller G, Davis J, Shatzen E, Colloton M, Martin D, Henley CM. Cinacalcet $\mathrm{HCl}$ prevents development of parathyroid gland hyperplasia and reverses established parathyroid gland hyperplasia in a rodent model of CKD. Nephrol Dial Transplant. 2012;27(6): 2198-2205.
18. Wada M, Ishii H, Furuya Y, Fox J, Nemeth EF, Nagano N. NPS R-568 halts or reverses osteitis fibrosa in uremic rats. Kidney Int. 1998;53(2): 448-453.

19. Henley C, Davis J, Miller G, et al. The calcimimetic AMG 641 abrogates parathyroid hyperplasia, bone and vascular calcification abnormalities in uremic rats. Eur J Pharmacol. 2009;616(1-3):306-313.

20. Lopez I, Aguilera-Tejero E, Mendoza FJ, et al. Calcimimetic R-568 decreases extraosseous calcifications in uremic rats treated with calcitriol. J Am Soc Nephrol. 2006;17(3):795-804.

21. Ivanovski O, Nikolov IG, Joki N, et al. The calcimimetic R-568 retards uremia-enhanced vascular calcification and atherosclerosis in apolipoprotein E deficient (apoE $\mathrm{E}^{-/}$) mice. Atherosclerosis. 2009;205(1):55-62.

22. Kawata T, Nagano N, Obi M, et al. Cinacalcet suppresses calcification of the aorta and heart in uremic rats. Kidney Int. 2008;74(10): $1270-1277$.

23. Tsuruta Y, Ohbayashi T, Fujii M, et al. Change in coronary artery calcification score due to cinacalcet hydrochloride administration. Ther Apher Dial. 2008;12 Suppl 1:S34-S37.

24. Raggi P, Chertow GM, Torres PU, et al. The ADVANCE study: a randomized study to evaluate the effects of cinacalcet plus low-dose vitamin D on vascular calcification in patients on hemodialysis. Nephrol Dial Transplant. 2011;26(4):1327-1339.

25. Ohya M, Otani H, Kimura K, et al. Vascular calcification estimated by aortic calcification area index is a significant predictive parameter of cardiovascular mortality in hemodialysis patients. Clin Exp Nephrol. 2011;15(6):877-883.

26. Guideline Working Group, Japanese Society for Dialysis Therapy. Clinical practice guideline for the management of secondary hyperparathyroidism in chronic dialysis patients. Ther Apher Dial. 2008;12(6):514-525.

27. Schneider CA, Rasband WS, Eliceiri KW. NIH Image to ImageJ: 25 years of image analysis. Nat Methods. 2012;9(7):671-675.

28. Bellasi A, Ferramosca E, Ratti C, Block G, Raggi P. Cardiac valve calcification is a marker of vascular disease in prevalent hemodialysis patients. J Nephrol. 2012;25(2):211-218.

29. Raggi P, Bellasi A, Gamboa C, et al. All-cause mortality in hemodialysis patients with heart valve calcification. Clin J Am Soc Nephrol. 2011; 6(8):1990-1995.

30. Walsh CR, Cupples LA, Levy D, et al. Abdominal aortic calcific deposits are associated with increased risk for congestive heart failure: the Framingham Heart Study. Am Heart J. 2002;144(4):733-739.

31. Shantha GP, Kumar AA, Mancha A, Christopher M, Koshi R, Abraham G. Is abdominal aortic calcification score a cost-effective screening tool to predict atherosclerotic carotid plaque and cardiac valvular calcification in patients with end-stage renal disease? Indian J Nephrol. 2012;22(6):431-437.

32. Wilson PW, Kauppila LI, O'Donnell CJ, et al. Abdominal aortic calcific deposits are an important predictor of vascular morbidity and mortality. Circulation. 2001;103(11):1529-1534.

33. Honkanen E, Kauppila L, Wikstrom B, et al. Abdominal aortic calcification in dialysis patients: results of the CORD study. Nephrol Dial Transplant. 2008;23(12):4009-4015.

34. EVOLVE Trial Investigators, Chertow GM, Block GA, et al. Effect of cinacalcet on cardiovascular disease in patients undergoing dialysis. N Engl J Med. 2012;367(26):2482-2494.

35. Thakore P, Ho WS. Vascular actions of calcimimetics: role of $\mathrm{Ca}(2)$ $(+)$-sensing receptors versus $\mathrm{Ca}(2)(+)$ influx through L-type $\mathrm{Ca}(2)(+)$ channels. Br J Pharmacol. 2011;162(3):749-762.

36. Koizumi M, Komaba H, Nakanishi S, Fujimori A, Fukagawa M. Cinacalcet treatment and serum FGF23 levels in haemodialysis patients with secondary hyperparathyroidism. Nephrol Dial Transplant. 2012;27(2):784-790.

37. Fukagawa M, Yokoyama K, Koiwa F, et al. Clinical practice guideline for the management of chronic kidney disease-mineral and bone disorder. Ther Apher Dial. 2013;17(3):247-288. 


\section{Publish your work in this journal}

The International Journal of Nephrology and Renovascular Disease is an international, peer-reviewed open-access journal focusing on the pathophysiology of the kidney and vascular supply. Epidemiology, screening, diagnosis, and treatment interventions are covered as well as basic science, biochemical and immunological studies. The journal welcomes original research, clinical studies, reviews \& evaluations, expert opinion and commentary, case reports and extended reports. The manuscript management system is completely online and includes a very quick and fair peerreview system, which is all easy to use. Visit http://www.dovepress.com/ testimonials.php to read real quotes from published authors.

Submit your manuscript here: http://www.dovepress.com/international-journal-of-nephrology-and-renovascular-disease-journal 